\title{
Discussion on the Service of University Archives to the Construction of Campus Culture
}

\author{
Shumin Cui \\ Management of teaching and research base, Jilin Agricultural University, Changchun,China
}

Email: cuishuminc@126.com

Key words: university archive; cultural function; method

\begin{abstract}
The university archive is a true record of reform and development in universities and is also an important part of the cultural heritage of colleges and universities. It is inextricably linked with the construction of campus culture. This paper analyzes the cultural function of the university archive and puts forward five ways to highlight the functions of university archive so as to promote the construction of university culture.
\end{abstract}

\section{Introduction}

University is a kind of unique organizations which has a long history of tradition and deep culture and plays a huge role in promoting economic development and social progress. With the deepening of the current reform of higher education, university culture is having an increasingly significant impact on university reform. The success of university reform depends on whether the university culture is good or not to some extent. Therefore, to build a first-class university, we must have a good university culture and struggle to choose, establish, and form a distinctive university culture. As the heritage and original records of university history, university archives possess inherent cultural connotation. Its culture storage, dissemination and educational function play an important role in building university culture.

\section{The Important Cultural Functions of University Archive}

\section{A. The cultural heritage functions of university archive}

University archive records not only various aspects of university teaching, research and party management, but also a large number of previous knowledge, recommendations, lessons learned, and so on. After a review of archival material, the situation can be completely controlled and the purpose of scientific decision can also be achieved. Improving the management level is the important guarantee for completing teaching task, propelling various reforms, and promoting the development of education. A very important condition for improving the management level is to be good at summing up the past management experience and learn from the previous management. Archival work collects the management activities of universities in each period. There are many lessons learned from the management described in the file, which are a valuable asset of management. The development of things is always inseparable from the original foundation ${ }^{[1]}$. The improvement of university management is also continuously improved and being perfected on the basis of the original foundation. By conducting the archival work in a solid way and summing up the previous management experience conscientiously, the truth "Taking history as a mirror, we can rule the world" can also be applied to the management of universities.

\section{B. The communication functions of university archive}

The edit of school history archives is an important form of cultural transmission of universities. During the process of the editing, publishing, and exhibition of school history, the image of 
university is deeply depicted in everyone's mind, which inspires them to love it more and do a better job and dedicate themselves to the development of university. The publication of school history also expands the social influence and visibility of universities and enhances their competitiveness in the educational market. University archive is the yesterday and history of university which records its growth. Under the increasingly competitive higher education market of nowadays, exerting the communication functions of university archive is important in expanding its influence and visibility, striving for establishing the brand of higher education, having a place in the education market, promoting the development of university education, and fostering the establishment of socialist spiritual civilization, etc.

\section{The education functions of university archive culture}

The cultural property of archive determines it possesses educational function. It is an important part for the school to strengthen moral education that conducting revolutionary tradition education to students by utilizing university archive. The education functions of university archive culture are mainly reflected in two ways: the preparation of school history and the compilation of character files $^{[2]}$. Facing the living history will inspire people's honor and pride of taking school as honor and respecting teachers. The establishment of university's character files can not only reflect the strong faculty members and scientific research strength, but also enhance the visibility and competitiveness of university by these character files, so as to establish the leader image of university education, academic and research base. Meanwhile, the codification of character file further inspires the next generation's ambition to learn from the predecessors and keep pioneering, which also reflects the college image of "respect knowledge, respect talent, and people-oriented".

\section{Exerting the Functions of University Archive And Ways to Promote Cultural Establishment}

\section{A. Taking the university archive into the track of construction of campus culture}

With the gradual deepening of campus culture construction, there is a huge change in the using demand of the functional departments of universities and the majority of users to archives. They are no longer confined to the use of the files themselves, but to a higher level of cultural products of archives. Take the university archive into the track of construction of campus culture and conduct unified planning and simultaneous development. On the one hand, the archive work should be included while the university makes the overall planning of campus culture construction, which requires the archives department must actively and closely cooperate with relevant departments on campus culture construction and develops various forms of archival information resources through cooperation and mutual assistance ${ }^{[3]}$. On the other hand, university's administrative departments should regard archive work as a part of assessment and evaluation while formulating the examination and evaluation approaches and campus culture. Standardize university archives to play a role in campus culture construction from the institutional level. Take full advantage of all kinds of existing files and personnel resources and technical resources to develop service strategies at the same time. Innovate service concept and standardize service behavior. Keep improving management level and service capabilities and strive to turn University Archive (chamber) into a true, complete and effective gathering place of "Campus memory", so as to better provide information support for the construction of campus culture and development.

\section{B. Strengthen the awareness of university archives' being a part of the construction of campus culture}

University archive clearly reproduces the exciting moments of the university's history, which has significant consultative and referential meaning for the construction of university campus culture. Colleges and universities must strengthen the awareness of their archives' being a part of the construction of campus culture. First of all, university administrators should recognize university archive is an invaluable source of information of the construction of campus culture, the management of which must be paid attention to. Secondly, university archivists should take the initiative to understand the function of university archive to the construction of campus culture and 
its relevant dynamics. Develop archive actively and innovate its cultural products. Ensure its cultural function to be maximized to make the university archives department truly become a solid base for the construction of campus culture. Finally, the majority of the users should also raise the awareness of using university archives to solve various problems in the construction of campus culture $^{[4]}$. They should also correctly understand the responsibilities and mission of university archives sector.

\section{Enrich and optimize the information resources of university archive}

In order to meet the actual needs of campus cultural construction, it is necessary to actively carry out the enrichment and optimization of archival information resources, which makes all kinds of files it collected gradually have the features of complete range, carrier diversity, reasonable structure and rich culture, etc. Therefore, lay a rich material foundation and prerequisite for the development and utilization of university archives information resources to serve the campus cultural construction and improvement. Firstly, the university archives departments should keep up with the pace of society and update the collection range of archives information resources. Conduct the collection of archives information resources reasonably and ensure that the archives of different categories and different carriers formed in various business activities of university can be properly filed and stored. Secondly, the university archives department should adhere to the concept of "people-oriented" in the collection work and take meeting the information needs of the user as the starting point of its work. On the basis of the traditional collection of archival information resources, actively carry out the collection of archives of cultural and educational value which are close to teachers and students and close to the public. Moreover, with the construction and development of digital campus, university archives sector should take advantage of this favorable opportunity to actively carry out the digitization of archives information resources. Strive to achieve the integrated management of all college archives information resources. Lay a solid foundation for the scientific development of archival information resources to better serve the construction of campus culture. Finally, in order to better serve the construction of campus culture, the university archives department should work closely with various functional departments, colleges, and all teachers and students. Actively carry out various collection work of file information of cultural and educational value, such as the diaries, letters, manuscripts, photographs of famous experts and scholars, prominent alumni and other figures of the school history, so as to achieve the target of rich collection and characteristics reflected ${ }^{[5]}$.

\section{Apply modern information technology and equipment to university archive}

Modern information technology and equipment can activate archival information resources of all kinds of files and better demonstrate its hidden rich connotation. It also offers a variety of means for the university archives to serve the construction of campus culture. A lot of practice has proved that university archives apply modern information technology and equipment in order to be developed and used efficiently and serve the construction of campus culture. It can both accelerate the processing speed of archival information resources and greatly improve the quality and efficiency. These devices are also the essential resource foundation of university archives information resources to serve the public and serve the construction of campus culture.

\section{E. Innovate cultural products of archives and broaden service channels}

University archives department should innovate cultural products of archives and broaden service channels according to the hotspots of the construction of campus culture. Specifically, the following should be included: (1) Actively carry out archival compilation and provide knowledge-based resource usage services. University archives departments should actively carry out the archival compilation of all kinds of archival information resources in their daily work to achieve the effective integration and high degree of sharing of information resources. (2) Establish the History Museum, the Museum and organize various thematic exhibitions to broaden the service channels of university archives to the construction of campus culture. It can not only greatly improve the status of university archives work, but also realize the interaction between university 
archive sectors and the users, thus better give play to its cultural functions and educational functions.

\section{Conclusion}

University archive is the source of university culture and the rare information resources for the construction of university, which provides an inexhaustible motive force for the university cultural heritage and innovation. Therefore, we should pay full attention to the work of university archive and utilize it to make universities form their cultural connotation with its own characteristics. This is not only conducive to the development of the school and the healthy growth of college students, but also conducive to the prosperity of socialist culture modernization.

\section{References}

[1] Zhang Bin. The construction of university based on the perspective of the construction of campus culture. [J]. Archives Space, 2011 (12):41.

[2] Xue Kuangyong. On the functions expansion and realization of Archives. [J]. Archives Science Study, 2010 (1):20-21.

[3] Wang Lin. Archives and the Construction of Campus Culture. [J]. Heilongjiang Archives, 2009 (4).

[4] Wang Yongjun. Promote the connotation construction of local universities' culture by making full use of archival resources. [J]. Lantai World, 2010 (2):37-38.

[5] Wei Xiaoqing. Promote the construction of campus culture by exerting the function of university archives. [J]. Ascent, 2011, 30 (2): 127-129. 